\title{
Primitive Self-consciousness and Avian Cognition
}

\author{
Andy Lamey \\ Monash University
}

\section{Abstract}

This is an uncorrected author's draft of a paper published in The Monist, Volume 95, Issue 3 (July 2012). For citation and quoting purposes, please use the published version.

Recent work in moral theory has seen the refinement of theories of moral standing, which increasingly recognize a position of intermediate standing between fully self-conscious entities and those which are merely conscious. Among the most sophisticated concepts now used to denote such intermediate standing is that of primitive self-consciousness, which has been used to more precisely elucidate the moral standing of human newborns. New research into the structure of the avian brain offers a revised view of the cognitive abilities of birds. When this research is approached with a species-specific focus, it appears likely that one familiar species, the chicken (Gallus gallus domesticus), also exhibits primitive self-consciousness. Given the likelihood that they are primitively self-consciousness, chickens warrant a degree of moral standing that falls short of that enjoyed by persons, but which exceeds the minimal standing of merely conscious entities.

\section{Keywords}

Animal cognition, primitive self-consciousness, moral standing, neuroethics

\section{Introduction}

Contemporary research into the structure of the avian brain has triggered a major shift in our understanding of avian cognition. For a century, scientists thought that the neocortex was a prerequisite for higher cognition. As the neocortex is found only in mammals, research into the cognitive abilities of other animals was considered pointless, as birds were assumed to lack the brain feature necessary for malleable, that is, non-instinctive, behaviour. In recent decades however it has emerged that functions performed by the neocortex in mammals are performed by different parts of the avian brain. This has caused the Avian Brain Nomenclature Consortium, an international group of neuroscientists, to overhaul the terminology that scientists used for 100 years to identify different parts of the avian brain (Avian Brain Nomenclature Consortium: 2005).

According to the consortium, the new picture of the avian brain "sets the stage for a re-evaluation of the cognitive abilities of birds" (Avian Brain Nomenclature 
Consortium 2005: 156). Just such a re-evaluation is now being undertaken by animal scientists in many different fields. One suggestion they increasingly make is that the new picture of avian cognition calls into question the popular notion that primates occupy a position of exceptional cognitive standing among animals. Such a view is expressed for example by Nathan Emery and Nicola Clayton, an animal behaviourist and experimental psychologist, respectively, at Cambridge University. "Why have primates achieved this special status when the evidence suggests that species of birds have cognitive abilities that are equal to or more sophisticated than have been demonstrated for primates?" (Emery and Clayton 2004: 36-7) A similar viewpoint is taken by Lesley Rogers and Gisela Kaplan of the Centre for Neuroscience and Animal Behaviour at the University of New England. They note that recent animal cognition research "challenge[s] the concept that primates are special and even the view that the cognitive abilities of apes is more advanced than that of non-primate mammals and birds" (2004: vii). The same point is made in regard to chickens by Lucia Regolin, a psychologist at the University of Padua, and three co-authors. Regolin and her colleagues point out that domestic chicks have "striking abilities to maintain working memories of the location of biologically attractive objects that parallel or outperform those of most mammals, including primates" (Regolin et al. 2005: 855)

If animal scientists across disciplines have noted the significance of the new understanding of avian cognition, the same is not true of moral philosophers. Although it is common for moral theorists to ascribe different degrees of moral standing to entities with different degrees of cognitive ability, to my knowledge, no moral philosopher has noted of the revised view of avian cognition and inquired into its ramifications for our understanding of the moral standing of birds. This is surprising, given that recent work in moral theory has seen the refinement of 
theories of moral standing, which increasingly recognize a position of intermediate standing between fully self-conscious entities and those which are merely conscious. ${ }^{1}$ Among the most sophisticated concepts now used to denote such intermediate standing is that of primitive self-consciousness, which has been used to more precisely elucidate the moral standing of human newborns. Given the revised view of avian cognition, it is worth asking whether any species of bird might also possess primitive self-consciousness and, if so, what degree of moral standing this entails.

Executing this project requires bringing sophisticated moral concepts to bear on cutting-edge neuroscience. On a conceptual level, it requires noting just what primitive self-conscious amounts to, and why its adoption will mark an improvement for any moral theory that recognizes only two levels of standing. The version of primitive self-consciousness best deployed in this regard, I argue, is one that innovates on previous versions, suitably revised so as to include a primitive ability to conceive of oneself through time. When the new avian cognition research is approached with a species-specific focus, it appears likely that one familiar species, the chicken (Gallus gallus domesticus), exhibits this type of primitive selfconsciousness. I focus on the chicken because it is a bird whose cognitive abilities have been extensively re-examined in recent years, and whose moral standing is of more than passing interest: more chickens may be killed by humans than any other

\footnotetext{
${ }^{1}$ In addition to Bermudez's notion of primitive self-consciousness, discussed below, Gary Varner also offers a systematic examination of a middle position between personhood and mere sentience, one which Varner labels that of near-personhood (Varner: forthcoming). Peter Singer endorses Varner's notion in the third edition of Practical Ethics (2011:103). For a similar idea, see Michael Tooley's notion of a quasi-person (1983: 424). Jeff McMahan mentions in passing the notion of an "intermediate status" between personhood and sentience, without exploring the notion (2002: 265).
} 
land animal. ${ }^{2}$ Given the likelihood that they are primitively self-consciousness, chickens warrant a degree of moral standing that falls short of that enjoyed by persons, but which exceeds the minimal standing of merely conscious entities.

\section{Primitive Self-Consciousness}

Many moral theories divide entities with moral standing into two categories, persons and non-persons. Theories differ in how they distinguish persons from nonpersons, but roughly speaking, it is common for personhood to be extended to entities that are not merely conscious but self-conscious. Non-persons with moral standing, by contrast, are typically merely conscious, or sentient. To be sure, there are theories of animal ethics which deny that self-conscious entities warrant a greater degree of moral standing than merely sentient ones. ${ }^{3}$ But the counter-intuitive implications of such theories can be seen by considering their implications for lifeboat scenarios in which, all else being equal, we must chose between saving a normal adult human and a dog. On such approaches, the greater cognitive abilities of the human afford no reason to save her life over that of the animal. It is perhaps unsurprising that the most influential theories of animal ethics do in fact ascribe higher moral status to self-conscious beings, which seems a reasonable distinction to draw (Singer 1990: 5-6, Regan 2004: 351). ${ }^{4}$

\footnotetext{
${ }^{2}$ According to the Food and Agriculture Organization of the United Nations, in 2009 over 8.6 billion chickens were killed in the United States to produce meat. By contrast, only 3.3 million cattle were killed for the same purpose (FAOSTAT 2011). The difference is explained in part by the fact that a typical chicken carcass provides six lbs. of meat, while a cow's affords 1,200 lbs.

${ }^{3}$ Of such theories the most sophisticated is perhaps that of Sapontzis, who accepts the above mentioned implication regarding lifeboat scenarios (1987: 221).

${ }^{4}$ The fact that a deontologist such as Regan accepts that there can be situations in which it is acceptable to sacrifice a conscious entity to save a self-conscious one should remind us that such a view is not necessarily utilitarian. On Regan's view for example it is acceptable to sacrifice less cognitively advanced beings for the sake of self-conscious ones in what he terms "prevention cases," or those in which the only way to prevent some innocent being or beings to be harmed is to harm another (2004: 287). A utilitarian would accept sacrificing one
} 
Yet there is an intermediate category occupied by entities that exhibit something in between full self-consciousness and mere consciousness, namely, primitive selfconsciousness. The concept of primitive self-consciousness has been outlined by José Luis Bermúdez. Below I will defend a version of primitive self-consciousness that differs in an important way from Bermudez's version. It is helpful however to begin with an outline of Bermúdez's account. I will call Bermúdez's version of primitive self-consciousness the type-one version to distinguish it from my own, type-two, version. Bermúdez's analysis involves not only primitive self-consciousness itself, which is a conceptual category, but a detailed empirical discussion of one type of entity, human infants, whom Bermúdez argues exhibit primitive self-consciousness. These two features are closely intertwined in Bermúdez's discussion, and it will be helpful to take note of his empirical claims in order to illustrate what Bermúdez's pioneering version of primitive self-consciousness involves. It bears stressing however that my discussion of Bermúdez's empirical account is by way of illustration. My account is agnostic as to whether infants do in fact possess this trait. More important for my purposes is the category of primitive self-consciousness itself. This conceptual claims, unlike Bermúdez's empirical ones, I endorse (in modified form).

Type-one primitive self-consciousness has been put forward as involving three central features. Shaun Gallagher itemizes them in a summary that builds on Bermúdez's account:

being to save another of higher moral standing in a much wider range of contexts. My account does not offer a final account of how often and under what conditions such trade-offs will be permissible, and entails only that such trade-offs are permissible in prevention cases (lifeboat scenarios). 
1. A body schema, defined as a subpersonal control mechanism that, in an immediate and close to automatic fashion, provides the capacity to control posture and movement. ${ }^{5}$

2. A differentiation between self and other.

3. A recognition that the other is of the same sort as oneself (Gallagher 1996: 133-4)

In order to better understand these three features, it is helpful to note their original use, which was to argue for a revised view of the cognitive abilities of newborns.

A longstanding view in the child development field has held that infants under 812 months are not capable of so-called invisible imitation, or imitation of another individual's movements using parts of the infant's body that are invisible to it, such as its face. According to Piaget and other influential theorists, this was because the infant did not have a body schema, understood as a proprioceptive awareness of its own body. Proprioceptive awareness in this usage refers to an awareness of the location of one's hand when it is behind one's back or an awareness that one is smiling without looking in a mirror.

Studies begun in the 1970s challenged the traditional view. They saw infants as young as one day old engage in imitative behaviours involving facial acts, such as mouth opening and tongue protrusion. An experimenter would perform the action while the infant had a dummy in its mouth. After the dummy was removed, the infant would repeat the modelled action. Given that this was impossible on the

\footnotetext{
${ }^{5}$ Body schema is sometimes distinguished from the more complex notion of body image. As Gallagher says of the latter, "body image, when fully developed, is a system of perceptions, beliefs, and attitudes about one's own body. As such the body image involves a reflective intentionality in which one's own body is the intentional object” (1996: 133). Bermúdez does not distinguish between body schema and primitive body image, but Gallagher persuasively argues that the former is all that primitive self-consciousness presupposes (1996: 133).
} 
traditional understanding, the experiments seemed to show that very young infants had several attributes the traditional picture overlooked. ${ }^{6}$

One was a body schema (Gallagher 1996: 133). This was because awareness of the gesture to be imitated and awareness of the imitating action occur in different sensory modalities ( Bermudez 1996: 389). A visual stimulus is followed by an action involving a part of the infant's body, the face, which the infant cannot see, but is rather aware of due to its proprioceptive awareness. The ability to "perceive and act upon intermodal equivalences" in this way requires the existence of some sort of body schema, because such a schema is a basic prerequisite of the integration of perception and motor commands (Bermúdez 1996: 390).

Bermúdez argues that the experiments also demonstrate that an infant is able to distinguish between itself and an other of the same sort as itself. His claim here has to do with the nature of imitation, which he takes to presuppose a rudimentary grasp of the self-other distinction. The infant, Bermúdez suggests, has to have at least a dim comprehension of the fact that the entity it observes is one whose action it can copy:

Not only do these infants have to grasp the intermodal equivalence of, say, a perceived tongue protrusion and their own act of protruding their tongue, but they also have to grasp that the perceived tongue protrusions is the sort of thing that they can imitate, as opposed, for example, to the movement of a nipple, to which they respond by sucking rather than by trying to imitate it (1996: 390).

When the infant sees a nipple, it responds by attaching itself to it. When it sees an experimenter sticking out her tongue, by contrast, it responds by sticking out its own tongue. This second type of reaction would appear to presuppose an awareness that the experimenter is doing something of which the infant itself is capable. Or as Bermúdez puts it, the infant's level of awareness "seems to involve a grasp that the

\footnotetext{
${ }^{6}$ The experiments in question are Meltzoff and Moore 1977; Meltzoff and Moore 1983; Field et al. 1982.
} 
experimenter is a being like themselves, in at least the sense that they are constructed in more or less the same way" (Bermúdez 1996: 390). If that is the case then the infant is aware, however dimly, that the experimenter and it are different entities with some sort of affinity. That would appear to demonstrate some minimal awareness of the self-other distinction, and an awareness that the other is somehow similar to itself.

If these conditions hold, Bermúdez argues, then the infant has a crude form of self-consciousness. A body schema for example would appear to be a kind of selfawareness, if only the awareness that one is an embodied or physical being. This is a primitive form of self-consciousness that the more sophisticated or full versions draw on, as a body schema informs our sense of what our possibilities for action are (Bermúdez 1996: 390). Similarly, the infant's imitative response would suggests that it is aware of a similarity between two entities, one of which is itself. This awareness again may be quite rudimentary, but its content concerns the nature of the infant itself. In particular, it is aware of possessing at least one possibility for action compared to the entity it observes. In taking that entity's actions as inspiration for its own, it thus appears to manifest some limited awareness of self.

Before completing our exegesis of type-one primitive self-consciousness, it will be helpful to note the relationship between primitive self-consciousness and its more full-blown counterpart. Exactly how is the first form of self-consciousness a more primitive version of the latter? To answer this question we need to note two features of self-consciousness proper.

The first is a capacity for reflexive self-reference, as when we refer to ourselves using the first-person pronoun. This capacity to single ourselves out in a reflexive way makes possible many of the high-level cognitive actions we associate with full self-consciousness. According to Bermúdez, they include the "capacity to make and 
reflect upon plans for the future, to form second order desires, and to fit together autobiographical memories into the narrative of a single life" (1996: 391) Reflexive self-referencing has other components, but one important aspect is that it is a tool self-conscious subjects can use to distinguish themselves from other self-conscious subjects. Using the first person pronoun is a way of "delimiting oneself as the object being spoken or thought about," as distinct from other self-conscious beings one might think or speak about (1996: 391).

The second noteworthy feature of full self-consciousness is essential selfknowledge, or knowledge of the sort of being that one is. In the case of adults, this might include the knowledge that one is an embodied human being, with powers of rationality, who is a member of a community with other such beings, etc.

Bermúdez's central claim is that infant imitation behaviour displays a primitive form of both of these features of full self consciousness. The understanding of the distinction between self and other that an infant displays in imitating an experimenter's behaviour is an early form of the much more complex distinction between self and other that occurs in full self-consciousness through reflexive selfreference. Similarly, the infant on Bermúdez's account displays a rudimentary form of essential self-knowledge by grasping that it is a being like the experimenter. Another way to say this is that the infants manifest a certain degree of essential knowledge and employ it to govern their interactions with the experimenter. This was suggested by their awareness that the acts they see are ones they can perform. Such an awareness is a kind of self-knowledge. To be sure, it is a far less developed form of self-knowledge than the full-blown version, which is entirely conceptual and propositional, while the baby's version is more akin to knowing-how than knowingthat. Nevertheless, the two forms of self-knowledge are on the same developmental continuum. And so the baby's self-knowledge stands in the same relation to an 
adult's as its crude grasp of the self-other distinction stands in relation to a more sophisticated version that is manifest through reflexive self-reference.

To sum up our exegesis of Bermúdez, what is important on his analysis is not an infant's capacity for imitation as imitation. Imitation rather bespeaks some minimal level of self-awareness. ${ }^{7}$ If we conceive of self-consciousness as a spectrum, with full self-consciousness at one end, and a much more minimal version at the other end, the infant seems conscious of itself enough to be just inside the boundary of the primitive level of self-consciousness. That is not very impressive when we have full self-consciousness in mind. But it is more than would be true of an entity that was conscious, with absolutely zero degree of self-consciousness, not enough even to know it could imitate what it was seeing.

Now one possible objection to this interpretation of infant imitative behaviour is to say that what is happening is a reflex. On such a view, the infants are not exhibiting any degree of self awareness, but are rather exhibiting an "innate releasing mechanism," or a pre-programmed response to perceived events exhibiting a common structure (Bermúdez 1996: 392). This view however is normally taken to apply to actions that occur without the involvement of memory: rather the stimulus arrives and is met with the pre-programmed action in question. In the case of the infant experiments, however, the infant has a dummy in its mouth when it sees the model behaviour and only later imitates it. This means there must be a stored representation of the model's facial gesture that triggers the infant's imitation, in a manner that seems distinct from how innate releasing mechanisms are usually understood. Bermúdez also notes that the infants in the experiments corrected their responses over time, and trial and error activity is normally thought not to be

\footnotetext{
${ }^{7}$ Bermúdez also suggests that an infant's initial act of imitation activates its primitive self-consciousness. See below.
} 
characteristic of reflexive behaviour. If so this provides an additional reason to reject the reflex interpretation.

\section{Derived Moral Significance}

This concludes our outline of type one primitive self-consciousness. As we will see, the version outlined below has an important difference with Bermudez's account. But an important feature both accounts share is a common source of appeal. Both make appeal to the principle of derived moral significance, or the DMS principle for short. It takes the following form:

If a particular feature or property is deemed to confer moral significance upon a life that has it, then any primitive form of that feature or property will also confer moral significance, although not to the same degree (Bermúdez 1996: 383).

Such a principle entails that if a property or attribute is morally salient, then any entity which has a primitive form of that attribute also possesses a corresponding degree of moral significance. Applied to the property of self-consciousness, the DMS principle will entail that any entity that is primitively self-conscious is also possessed of a morally salient trait, albeit not to the same degree as an entity that exhibits full self-consciousness. The primitively self-conscious entity, importantly, possesses this morally significant trait independently of any other morally significant attributes it might possess (such as, for example, a capacity for suffering).

In order to better understand the DMS principle, it will be helpful to note two claims it does not entail. It does not entail that an individual being which is currently conscious, and in the normal course of events will become self-conscious, possesses some additional degree of moral standing in virtue of its potential for selfconsciousness. An infant for example is conscious and in the normal course of events will become a person, and there have been moral theories which have sought to ascribe moral significance to this potential personhood. The DMS principle is not like 
this: it makes no reference to potentiality. Rather it ascribes value to primitive selfconsciousness insofar as it is an existing feature of a living thing, and only insofar as it is an existing feature. The claim is that an account which makes the existence of a particular trait morally significant "ipso facto makes the existence of primitive forms of that feature morally significant" (Bermúdez 1996: 385). Potentiality of any kind never enters into the analysis.

A second claim the DMS principle does not entail is that if an entity exhibits a primitive form of a morally significant property, then it will necessarily go on to possess that property in a fuller form. It is rather possible for the proportionate moral significance which the principle generates to apply to an entity that will never possess the full version of the attribute in question. We can imagine a human being who is cognitively disabled, such that his course of development does not follow the normal path leading to full self-consciousness. Instead he reaches the stage of primitive self-consciousness and stops there. The DMS principle would ascribe moral significance to this limited amount of self-consciousness, albeit, of course, less significance than that possessed by a fully self-conscious person. In a similar way, the DMS principle can also apply to a member of a species which does not have the capacity for full-self consciousness, but does exhibit a primitive form of selfconsciousness.

Why adopt the DMS principle? One reason is because it avoids classifying sentient beings into one of only two categories of moral standing. As mentioned above, moral theories frequently divide entities with moral standing into persons and non-persons. Let us refer to such two-level theories with the shorthand term personhood theories. It is common for personhood theories to maintain that every sentient being below the level of a person has the same degree of intrinsic moral 
standing (I say intrinsic in order to set aside moral issues having to do with personal relationships and social roles).

Personhood theories do not seem able to capture the notion that there could be two sentient beings, neither of which was a person, but which nonetheless occupy different positions of moral worth. An ape and a fish, for example, may both fall short of personhood. But this fact, by itself, does not necessarily entail that they both must possess an equal degree of moral standing. It is at least possible that the ape, which may have cognitive abilities beyond that of the fish, deserves a heightened position of moral standing. Such a position may fall short of that of a person.

Nevertheless it could still make a moral difference, such that if we had to choose between killing the ape or the fish, it would be less wrong to kill the fish. Given the diversity of living things, it seems an advantage of a theory of moral standing if it can at least admit such a possibility in principle, without presuming in advance that any particular animal does in fact occupy a position of worth below personhood but above that of a merely sentient creature.

A theory that admits at least the possibility of an intermediate status between sentience and personhood will respect the DMS principle and be more nuanced and subtle than a theory that lacks any intermediate stage. ${ }^{8}$ Given the overwhelming diversity of animal life, and the fact that all theories of moral standing ascribe moral significance to the intrinsic properties of living things, it is reasonable to see a theory

\footnotetext{
${ }^{8}$ This nuance and subtlety however need not entail an extensive series of stages of moral value beyond the three argued for here (sentience, primitive self-consciousness and full self-consciousness). The presence of any degree of self-consciousness is metaphorically the difference between zero and one, a difference one can ascribe significance to, while stopping short of the claim that every additional degree of self-consciousness is equally significant. It is the presence of something not found at all in merely sentient creatures that makes primitive selfconsciousness a crucial threshold, in a way that does not necessarily carry over to creatures which possess a degree of self-consciousness in between the primitive and full levels. While one might argue for such a highly graduated or four-level theory of moral standing, it is not strictly entailed by the principle of derived moral significance.
} 
that is better able to reflect complexity in such properties as a better theory, all else being equal.

\section{Type-two Primitive Self-consciousness}

I turn now to outlining a notion of primitive self-consciousness that incorporates an important new element. Whereas Bermúdez focuses on the possession of a body schema, an ability to distinguish between self and other and an awareness that an other is similar to oneself, I employ a notion of primitive self-consciousness that additionally includes some minimal ability to conceive of oneself through time.

Why adapt primitive self-consciousness this way? The ability to conceive of oneself through time is often cited as a morally relevant aspect of self-consciousness (Tooley, 1983, Singer 1993, Velleman 2000). The precise role this ability plays differs differ from one theory to another, but a common feature is its connection to the ability to form desires about the future. A person can form forward-looking desires, such that if the person is killed, it will prevent the attainment of those desires. Hence a person is deprived of something by death in a way that is not the case for an entity that is unable to form desires or expectations regarding its future. ${ }^{9}$

It is possible to conceptually separate the ability to conceive of oneself through time from the aspects of self-consciousness discussed by Bermúdez. One might imagine for example a hypothetical creature that conceives of itself through time but is unable to distinguish between itself and another, as it has never encountered another sentient being. In regard to real entities, however, it seems unlikely that an animal will possess an ability to conceive of itself through time but completely lack

\footnotetext{
${ }^{9}$ This is not the same as saying that being harmed by death depends on forming desires about the future. An entity could be harmed in other ways, as by, for example, being deprived of its future good. There are theories that hold that the negation of forward-looking desires and expectations is but one way death harms us (i.e. McMahan 2003). But on such theories forward looking desires etc. still affect a beings moral status as they increase the scope of the harm caused by death. On such views, death may harm sentient entities, but it harms primitively self-conscious ones even more.
} 
the aspects of primitive self-consciousness highlighted by Bermúdez. It seems rather in nature that cognitive ability is a "package deal," in that an entity is more likely to have some primitive ability to form expectations regarding the future if it possesses the features of primitive self-consciousness highlighted by Bermúdez.

If an ability to conceive of oneself through time and an ability to form desires regarding the future are morally salient aspects of full-self consciousness, then the principle of derived moral significance entails that a primitive ability to exercise such features will warrant an equivalent degree of moral significance. Applied to the ethics of killing, the ability of persons to form desires regarding the future is typically taken to warrant recognizing a presumptive right to life in their case (Tooley 1983; Singer 1993; Velleman 2000). ${ }^{10}$ The DMS principle suggests that if an entity is primitively self-conscious, it will not possess this same right. On the other hand, such an entity will have some interest in continued existence. It will be the kind of thing that can be harmed by death, in that it is deprived of something by being killed. I will try to outline below what moral entitlement best corresponds with this kind of primitive self-consciousness. The point at hand however is that a primitive ability to conceive of oneself though time is a morally salient attribute.

With these considerations in mind, let us now ask: do chickens possess primitive self-consciousness? Our concern here is with primitive self-consciousness not as Bermúdez defined it, but the type-two version that includes a primitive ability to

\footnotetext{
${ }^{10}$ My usage of the term "right to life" is not meant to entail any commitment to deontology or anticonsequentialism. It is rather a convenient shorthand for the degree of moral standing a person possesses, but which non-persons do not, when moral standing is determined without regard to the notion of time-relative interests. In this broad sense of the term, a right to life is something even a utilitarian can endorse, as it does not preclude killing one entity to achieve a greater good. Referring to a right to life is rather meant to express the general notion that killing a person requires greater justification than killing a non-person, in a manner that does not take a stand on precisely what that higher standard will involve, a subject on which different moral theories disagree, and which my account is not meant to settle.
} 
conceive of oneself through time and form expectations regarding the future. An animal is more likely to possess this ability if the animal possesses the aspects contained in type-one primitive self-consciousness. Is it conceivable that chickens might not only meet Bermúdez criteria of primitive self-consciousness, but also have some sense of time and the future?

It is relatively uncontroversial to ascribe greater cognitive abilities to chickens than to newborns. For example, the ability to retain recognition of partly hidden shapes, an ability possessed by two-day-old chicks, does not emerge in humans until 4-7 months (Lea and Ryan 1996). Tests of two-day-old chicks' abilities to recover fully occluded objects have also found that they mastered some aspects of stage four of the so-called Piaget Scale of object permanence, a level human infants do not begin to reach before three and half months of age (Regolin et. al. 1994, Regolin et. al. 1995; Baillargeon and DeVos 1991). ${ }^{11}$ Such findings are perhaps unsurprising when one considers the environment chickens are born into. As avian cognition researcher Giorgio Vallortigara points out, "recognition of a partly occluded mother would be useful when an organism can move by itself to rejoin the mother and thus reinstate social contact; that is the case for the highly precocial young chick, but not for the highly altrical species such as the human newborn" (2004: 62). The findings just mentioned do not seem to presuppose the existence of any form of primitive self-

\footnotetext{
${ }^{11}$ See Vallortigara 2004 61-2, 73-4, 80 for summaries of both experiments and the relative peformance of chicks and infants. Vallortigara also mentions a third study testing animals' ability to distinguish between different corners of a rectangular cage using only geometric information about the cage's layout. The animal was placed in the cage when food was located in a corner and made to disappear. After the animal was disoriented, it was allowed to search for the previously present food. More than one animal species was able to distinguish between different corners based only on the rectangular shape of the cage. According to Vallortigara, "the performance of birds in these tasks is identical to that of rhesus monkeys (and human adults) and clearly surpasses that of rats of human infants" (2004: 80).
} 
consciousness. They should nonetheless open us to the possibility that, here as elsewhere, chickens may be more cognitively advanced than newborns.

Is there any direct evidence for type-two primitive self-consciousness in chickens? Consider a recent study that investigated the behaviour of mother hens (Nicol and Pope 2005). The hens were exposed to two different food sources that had been treated with food colouring. One coloured food was edible while the other was not. The particular colours used varied from hen to hen, but for simplicity's sake we can imagine a hen choosing between a plate of yellow food pellets, all of which were edible, and a plate of blue ones, all of which were inedible. The hens quickly learned to avoid the unpalatable food. They were later exposed to their chicks participating in a series of feeding sessions in a neighbouring pen. Each hen had an even number of chicks, some of which ate food sources with similar colour coding: a mother who had been exposed to yellow edible crumbs and inedible blue ones would watch some of her chicks choose between sources with the same colour coding. Each mother however was also exposed to a second set of offspring, whose food options had a reverse colour coding, with the yellow now unpalatable and the blue palatable. So far as the hens could tell, the second chicks were making a mistake and opting for unpalatable food. The researchers wanted to know if this information would have any influence on the hens' behaviour.

They found that it did. Hens are known to engage in maternal food displays, or actions which facilitate the acquisition of feeding skills on the part of their chicks. Such displays include food calls and pecking movements directed toward both food items and the ground. After witnessing the second set of chicks eat the "wrong" food the hens significantly increased their maternal food displays, engaging in more intense scratching and ground pecking than after witnessing the first group. The researchers concluded that hens modified their own behaviour in response to 
perceived feeding errors by their chicks, seeking to instruct them in what type of food to avoid.

The behaviour of the hens and chicks provides as much evidence for type-one primitive self consciousness in chickens as the child development studies cited by Bermúdez support a similar judgement regarding infants. Recall that Bermúdez noted that a primitive body image was suggested by an ability to integrate visual perception and motor commands. The chicks and hens both do this when they opt for food of one colour and not another. (The hens additionally accelerate their food displays in response to the visual stimulus of watching their chicks eat.) Insofar as primitive body image is present in an entity that can use its body in a manner sensitive to what it sees, chickens pass the test.

The study also suggests that chickens meet Bermúdez's second and third condition, that of being able to distinguish between self and other, and to recognize that one is an entity of similar kind to another individual. This was the conclusion Bermúdez drew from the infants' ability to engage in imitative behaviour. Maternal food displays presuppose a similar ability on the part of both chicks and hens. The chicken researchers note that "newly hatched chicks peck at food and non-food items alike and have to learn which items are palatable and profitable" (2005: 768). Maternal food displays facilitate this type of learning, as the hen pecks at a palatable food item while vocalizing, or picks it up and drops it. In order for the chick to benefit from this type of behaviour it has to recognize that the hen is engaging in a behaviour, that of pecking at food, that it also can engage in. It has to be dimly aware that both it and the hen can eat the same thing.

Similarly, in order for the hen to be concerned about the chicks' perceived food error, she has to recognize an affinity between a chick's action and what she was doing when she ate the unpalatable food. She has to have some minimal awareness 
that the chick is doing what she did, which presupposes an awareness that the chick is the kind of thing that she is.

Bermúdez argued that the involvement of memory and trial and error each cut against the judgement that the infants are acting on instinct. Both attributes are present in the chickens' behaviour. Both the chicks and the hens are able to remember that food of a certain colour is unpalatable. After seven days of training, all subjects consistently avoided the unpalatable feed, a behaviour they maintained throughout the remaining four days of the experiment, during which less than one out of a thousand pecks were directed at unpalatable food. When the hens watched the chicks eat the "wrong" food and accelerated their display behaviour, they did so for one-hour periods. During the first half hour, the hens had no access to food of any kind, and had last eaten palatable food ninety minutes previously. In terms of the time since the hens had eaten unpalatable food, it had been at least 72 hours beforehand. When the hens intensified their displays in response to the chicks' perceived mistake, therefore, they were acting on a stored representation rather than an innate releasing mechanism or instinct.

The hens displayed no tendency to intensify their maternal displays in response to watching their chicks eat food of any particular colour. They rather changed their behaviour whenever they saw the chicks eat the food that was the same colour as their own unpalatable food, a colour which varied from hen to hen. It was not the colour per se that triggered their behaviour, in other words, but the memory that food of such colour was in their experience unpalatable. ${ }^{12}$

\footnotetext{
${ }^{12}$ The capacity of chickens to make decisions based on stored representations is well-supported by additional studies of chicken memory. Such studies have found that hens and chicks retain a memory not merely of the location but also the content of food caches (Forkman 2000, Cozzutti and Vallortigara 2001); that five-day-old chicks can determine the location of a moving object three minutes after it disappears, a result similar to that found in studies involving primates (Vallortigara et al. 1998); and that one-day-old chicks who observe another
} 
As for trial and error, it too is presupposed by the chicken's behaviour, as this is the context in which maternal food displays function. Baby chicks do not arrive in the world knowing what to eat. They learn where to direct their efforts by observing their mother's behaviour. As such they engage in a form of rudimentary trial and error behaviour, up to the same level of an infant refining a tongue protrusion or similar facial gesture. In that sense there is just as much evidence cutting against a purely instinctive or reflexive explanation in the case of the animal as in the case of the infant.

Chicks and chickens, just as much as infants, meet Bermúdez's criteria of type-one primitive self-consciousness. Turning now to type-two self-consciousness, is there any evidence to suggest that chickens have a primitive sense of the future? Here we turn to a recent experiment that found chickens can display self-control when choosing between two time-released food sources (Abeyesinghe et al. 2005). The chickens were trained to peck on one of two keys that would temporarily release a quantity of food into a trough after a short delay. Pecking the first key would release the food after a two second delay, and it would stay in the trough for three seconds before disappearing through a drop-away floor. Pecking the second key, by contrast, would release the food after a six-second delay; but it would stay in the trough for 22 seconds. The researched labeled the second choice the jackpot choice, as it allowed the chicken a much greater food access.

The experiment was designed to test whether chickens had a capacity for selfcontrol, with self-control understood as the ability to "resist immediate gratification for a later benefit" (Abeyesinghe et al. 2005: 2). The study found that the chickens' that they should not peck the bead themselves, and avoid doing so up to 24 hours after the observation (Johnston et al. 1998 see also Salva et al. 2009) . 
tendency to exercise such self-control was "significant and pronounced" (2005: 10). Of the seven birds trained to choose between the two options, all seven opted for the jackpot choice over 75 percent of the time. Five of the seven did so over 95 percent of the time. ${ }^{13}$ This overwhelming preference for the jackpot option suggests that the birds had some awareness of the short-term consequence of their decision regarding which key to push. As the researchers put it, "Our findings have demonstrated, first, that hens can discriminate between short time periods; second, that there is no absolute cognitive deficit preventing the hen from comprehending later consequences of food choices" (2005: 8). The experimenters do not claim to have shown precisely how far into the future hens can perceive: they note that little research has been conducted into this question to date. But the overwhelming preference of the birds for the jackpot food access over the impulsive option or random results does demonstrate an ability to see at least six seconds into the future. As the researchers put it, "although how far into the future hens can mentally travel has yet to be determined, we now know that they are not completely 'stuck in time'" $(2005: 8,10)$.

Consider now a third and final study, which also investigated whether chickens have some perception of time (Taylor et al. 2002). It saw five chickens successfully trained to peck a lit touch screen to obtain a food reward. After the chickens learned how to use the screen, the researchers introduced a time delay into the experiment. After the screen came on, six minutes would elapse before any food could be obtained. The first peck of the screen after six minutes had elapsed would result in

\footnotetext{
${ }^{13}$ The researchers noted that different results obtained when the amount of time required for the jackpot choice changed. When the jackpot choice was changed to involve a 22-second delay to a 22-second food access, for example, six out of eight chickens opted for the two-second wait for a three second feed access over 95 percent of the time. The researchers suggest that the different results may be due to the birds discounting the value of a more temporally distant reward (2005: 6).
} 
the food reward. The chickens were subjected to 150 training trials followed by 100 testing trials. Previous studies in other species have found that some animals respond less at the beginning of the delay period and more frequently after it has elapsed. "The advantage of this behaviour is that the food reward is obtained reliably and the effort used in obtaining it is reduced, due to the low rate of response at the beginning of the interval. The frequent response near the end of the interval allows food to be obtained as soon as it becomes available" (Taylor et al. 2002: 42). The results of the chicken experiments found that they too pecked the screen comparatively less during the first two minutes of the time delay, and accelerated their pecking so that it peaked in frequency between six and 7.5 minutes. The researchers' conclusions are tentative, among other reasons, because they were only able to perform a limited number of trials over a two-week period. Nevertheless, they take the results to raise the possibility that hens do have a limited perception of time. "The results indicate that domestic hens may have the ability to estimate the time to reward when given a reliable signal such as that given by the touch screen several minutes in advance" (2002: 49).

This experiment and that previously involving self-control are similar to that involving maternal feed displays, in that the behaviours under investigation were learned through trial and error. In both time experiments, the chickens had to be trained to use an experimental device. The behaviours in both time experiments equally presupposed some stored representation of what the animals had learned: they had to retain some memory of how the equipment worked from their training, and apply that knowledge to their use of it in the experiments proper. These considerations cut against the notion that the birds' activity in either experiment was purely instinctive. In the first experiment, the instinctive action would be to peck at either key with random frequency, with no sign of deliberation between the two. In 
the second, an instinctive response would be less likely to vary across time. Rather the bird would again peck in an indiscriminate way. The time experiments thus seem to demonstrate behaviours that can no more be characterized in reflex or instinctive terms than the behaviour of the infants in the experiment Bermúdez discusses or that of the chickens in the maternal food display study.

The time-perception studies suggest that chickens have a primitive aspect of the dimension of self-consciousness that involves a perception of oneself through time. Particularly in regard to the first time-study, the chickens were able to choose between two options that involved different rewards at different points in the future. As ever with primitive self-consciousness, the ability at hand is not very impressive when compared to its full-blown equivalent. But the perception of time in relation to their future is present nonetheless. This suggests that a reason that has sometimes been given for the permissibility of killing chickens, their lack of any awareness regarding the future whatsoever, may be based on a factually incorrect claim.

\section{The Benefit-of-the-Doubt Standard}

I say may be because our conclusions in this area would seem necessarily tentative. We are dealing with empirical findings that could potentially change. Nevertheless, I believe the above mentioned experiments show this much: it is reasonable to ascribe chickens whatever moral standing accompanies type-two primitive self-consciousness in a manner that gives them the benefit of the doubt.

What justifies giving the birds such a benefit? The reason has to do with a danger that comes with determining which entities possess any morally salient attribute. The danger is one of causing harm by failing to recognize the attribute's presence in a given entity. Investigating whether chickens possess primitive self-consciousness is not like investigating what colours their feathers are. When it comes to a morally irrelevant feature such as colour, we are not at risk of causing harm by employing an 
overly strict method of classification. But when it comes to a morally salient feature such as primitive self-consciousness, if the birds possess it and we fail to recognize this through an overly scrupulous standard of proof, we could potentially do something morally wrong. For example, we might kill them in a wider range of contexts than their cognitive abilities and corresponding moral status permit when properly understood. The best way to avoid this danger is to err on the side of recognizing primitive self-consciousness.

The legitimacy of a benefit-of-the-doubt standard would seem influenced by whether or not the evidence for the attribute under investigation is above some minimal threshold, a threshold that makes it at least possible that the attribute is present. For example, suppose an environmental ethicist were to argue that we should treat plants as persons. Imagine the environmentalist urged this view on us because it was at least open to doubt, and we should give plants the benefit of the doubt. Surely this would be a weak argument, given that there is no evidence that plants exhibit personhood.

When it comes to type-two primitive self-consciousness, by contrast, there is enough evidence to make its presence in chickens an open question. That should cause us to make claims about the species' moral standing in a manner that errs on the side of higher, rather than lower, moral ranking. This is not because we want to commit ourselves to unsupported views regarding animal cognition. It is rather based on a recognition of the difficulty of knowing what goes on inside the mind of creatures we cannot speak to directly. In the case of infants, for example, it seems reasonable to err on the side of extending them the protection of morality based on what we do know about them. The same interpretive stance should apply in our dealings with animals which, if anything, appear to have cognitive abilities beyond that of newborns. 


\section{The Moral Significance of Type-two Primitive Self-Consciousness}

If chickens do posses type-two primitive self-consciousness, what moral significance follows from this? One's answer to this question will inevitably be influenced by one's ethical theory. Most moral theories one encounters today however give some weight to the equal consideration of interests. ${ }^{14}$ As Peter Singer summarizes a simple version of this view, it entails that "the interests of every being affected by an action are to be taken into account and given the same weight as the like interests of any other being" (Singer 1990: 5). Equal consideration need not apply at the level of judging individual actions: one could also employ it to determine what type of rule to adopt. Similarly, a commitment to equal consideration can be found in deontological and utilitarian theories alike. ${ }^{15}$ While there is ongoing debate as to what equal consideration precisely entails, the basic notion of equal consideration is widely endorsed. It is therefore worth asking what difference type-two primitive self-consciousness makes when combined with some version of the equal consideration of interests principle.

It is often held that entities that are merely sentient are not harmed by death. ${ }^{16}$ They have no welfare interest in continued existence, and so are not deprived of

\footnotetext{
${ }^{14}$ Many philosophers have noted the presence of some form of equal consideration across a wide variety of otherwise different theories of ethics and political morality. They include Singer (1990: 6), Hare (1972: 167), Nagel (1979: 111), and Dworkin (1983: 24).

${ }^{15}$ As Will Kymlicka remarks, "both [deontological theories and utilitarianism] work from a basic moral commitment to the idea of impartiality. Both theories accept that, from the moral point of view, each person is equally worthy of moral consideration, each person is an end in herself, whose interests must be given equal consideration" (1991: 159).

${ }^{16}$ The widespread view that chickens are not harmed by death is my target in this paragraph. But note that my discussion of primitive self-consciousness in chickens will also affect their standing in ethical theories, such as McMahan's, which hold that merely sentient beings can be harmed by death. The presence of primitive selfconsciousness will increase the scope of the harm caused by death, and so make killing it that much worse than killing a merely sentient being.
} 
anything when they are killed, so long as it is done painlessly. The same however is not true of entities that possess type-two primitive self-consciousness, who do have at least some interest in continued existence. Although that interest is not on the scale of that possessed by persons, it is nonetheless significant, as it means that a primitively self-conscious entities has interests that need to be taken into account when we are deciding whether or not to kill it. In order for killing them to be justified, some morally significant greater interest needs to be advanced by their death. This means that while chickens can be killed for wide variety of reasons than persons, there are some instances in which it is wrong to kill them, even when they die painlessly.

How might we characterize such a level of moral standing? I believe it is best formulated in terms of what can be termed a "slow-to-kill" entitlement. Such a degree of standing is one that would permit killing a primitively-self conscious entity in a wider range of contexts than a person. If killing a bird was the only way to save a human life, for example, the slow-to-kill stance would license killing the bird. A person has greater cognitive abilities, including a greater ability to form expectations regarding the future. When comparing a life for a life, the person will lose more extensive welfare-interests when it is killed than will a primitively selfconscious entity. The person's interest in continued existence will outweigh the interest of the merely primitively self-conscious animal in its future. We can therefore legitimately say that in killing advances greater moral interest, with relative ranking determined according to the equal consideration standard.

By the same standard, however, the most common reason for killing chickens-so we can eat them-does not measure up. The animal loses its life when it does not really need to. For we could live without chicken in our diets. For this reason, there is not a real need at stake. Rather a moral wrong occurs when we kill a primitively 
self-conscious entity for such a purpose. The advertising that directs us to eat chickens because they are finger licking good, for example, would seem to reflect a morally trivial reason to kill them. That we enjoy how something tastes is not sufficient grounds to override its interest in continued existence. Indeed the mere fact that we take pleasure in eating an animals does not warrant any moral significance whatsoever.

This conclusion can be supported by way of a thought experiment designed to illuminate an often overlooked feature of equal consideration. ${ }^{17}$ Imagine an affluent society in which everyone has an equal share of resources. Within this egalitarian society there is a city block where everyone has a house and a lawn. All but one of the people living on the block plant a garden. They then turn around and demand that the last person's lawn be kept open for collective use as a park, even though the last block resident wants to plant her own garden.

There are moral theories which would endorse taking the last person's lawn. Preference utilitarianism, for example, takes equal consideration to involve the aggregation of pre-existing preferences. The homeowners who want to turn the lawn into a park outnumber the owner, so their action is just as it satisfies more preferences. Will Kymlicka however argues that what the homeowners do is wrong, on the ground that a concern for equality should enter into the very formation of our preferences. "Part of what it means to show equal consideration for others is taking into account what rightfully belongs to them in deciding on one's goals in life. Hence prejudiced and selfish prejudices are excluded from the start, for they already reflect a failure to show equal consideration" (1990: 42).

Kymlicka's understanding of equal consideration is intuitively plausible. But if we accept Kymlicka's restriction against selfish and biased preferences, then the desire

\footnotetext{
${ }^{17}$ The thought experiment is taken from Kymlicka (1990: 42).
} 
to eat an animal that is harmed by death will not be granted any moral weight. ${ }^{18}$ This is because the preference to eat such an animal is one that does not take account of the bird's interest in continued existence. This interest is entailed by its ability to form expectations regarding the future and a conception of itself through time, both of which are destroyed when it is killed. Given that the bird suffers a greater deprivation when it is killed than a person does when she must eat an alternative food source, especially an alternative source that is easily available, a preference that takes equal consideration into account at the level of its formation will be one that does not destroy the animal's interest for a purpose as trivial as eating it for reasons other than sheer necessity. Much like the homeowners preference for a better vista at the expense of their neighbour's welfare, the preference to eat an entity that is harmed by death can be said to exhibit a selfish disregard for the interest of the consumed animal, a refusal to recognize what is rightfully its. There is thus no interest to weigh against the animal's interest in continued existence, as the interest in satisfying the desire to eat such an animal is never recognized as a morally legitimate interest to begin with. ${ }^{19}$

\section{Conclusion}

\footnotetext{
${ }^{18}$ While I am here operating in an explicitly anti-utilitarian framework, I believe the avian cognition research I have cited will also have similar ramifications for some versions of utilitarianism. While the remark by Singer about equal consideration quoted above is not one which presumes the truth of utilitarianism, elsewhere in his writings Singer has adopted a consciously utilitarian framework. In this mode he argued that we have a substantial obligation to avoid killing entities which are capable of "conceiving themselves as distinct beings with a past and a future" (1993: 131). If I read Singer's correctly, to the degree that an entity possesses this ability at all, even to a degree that falls short of that of a normal adult human, then "the case against killing [it] is strong" (1993: 132). By that standard, when the new avian cognition research is analyzed in Singer's terms, the case against killing chickens is strong.

${ }^{19}$ I have been concerned with the ethics of killing a chicken merely to satisfy a culinary preference for meat. But if we would otherwise starve to death, the slow-to-kill principle would offer a more permissive judgement, whether or not we adopted Kymlicka's view of equal consideration, on the grounds that a fully self-conscious entity suffers a greater loss through death than a primitively self-conscious one.
} 
The new understanding of avian cognition means that claims that chickens are trapped in an eternal present can no longer be taken for granted. Such claims now require empirical evidence. Even if some of the new research is disproven, it should cause us to recognize the standard of proof that must be met in the debate over the killing of animals. Approaches that do not appeal to up to date research in animal cognition are no longer adequate.

My reading of the empirical literature on avian cognition is that chickens can reasonably be said to possess the moral standing that accompanies type-two selfconsciousness, when such moral standing is assigned in a manner that gives the bird the benefit of the doubt. And I have argued that the moral entitlement which best corresponds to this attribute is neither a right to life nor a kill-with-indifference stance, but a slow-to-kill stance. An upshot of this claim is that the most widespread form of meat eating in our society is indefensible. In a world in which billions of birds are killed for culinary purposes, this is moral knowledge worth having.

\section{References}

Abeyesinghe S., Nicol, C., Hartnell, S. and Mathes, M. (2005). "Can domestic fowl, Gallus gallus domesticus, show self-control?" Animal Behavior 70/1: 1-11.

Avian Brain Nomenclature Consortium (2005). "Avian brains and a new understanding of vertebrate brain evolution," Nature Reviews Neuroscience, 6/2: 1519 .

Bailey D, Rittenhouse L., Hart R and Richards R., (1989). "Characteristics of Spatial Memory in Cattle," Applied Animal Behavior Science, 23 / 4: 331-40.

Bailey, D., Howery L. and Boss D. (2000). "Effects of social facilitation for locating feeding sites by cattle in an eight-arm radial maze," Applied Animal Behavior Science, 68/2: 93-105. 
Baillargeon, R. and DeVos, J. (1991). “Object permanence in young infants: further evidence," Child Development 62 / 6: 1227-46.

Bermúdez, J. (1996). “The Moral Significance of Birth," Ethics, 106/1: 378-403.

Cozzutti, C. and Vallortigara G. (2001). "Hemispheric memories for the content and position of food caches in the domestic chick," Behavioral Neuroscience, 115/2:. 305-313. 40.

Dworkin, R. (1983). "In Defense of Equality." Social Philosophy and Policy 1(1): 24-

Emory, N. and Clayton N. (2004). "Comparing the Complex Cognition of Birds and Primates," in Comparative Vertebrate Cognition: Are Primates Superior to NonPrimates?, Rogers L. and Kaplan G (eds.). New York: Kluwer Academic.

Field, T., Woodsron, R., Greenburg, R., and Cohen, D. (1982). “Discrimination and Imitation of Facial Expression by Neonates," Science, 218: 179-81.

FAOSTAT (2011). Statistical database of the Food and Agricultural Organization of the United Nations. Available online at http: / / faostat.fao.org/ site/569

/ default.aspx\#ancor. Last accessed October 15, 2011.

Forkman B. (1998). "Hens use occlusion to judge depth in a two-dimensional picture," Perception, 27 / 7: $861-867$.

Gallagher, S. (1996). "The Moral Significance of Primitive Self-Consciousness: A Response to Bermúdez," Ethics, 106/3: 129-40.

Hare, R. M. (1972). "Rules of War and Moral Reasoning." 'Philosophy and Pubic Affairs 1(2): 166-181.

Johnston, A., Burns T. and Rose S. (1998). "Observation learning in day old chicks using a one-trial passive avoidance learning paradigm," Animal Behaviour, 56/3: 1347-53.

Kymlicka, W. (1990). Contemporary Political Philosophy: an Introduction. Oxford University Press, Oxford.

Kymlicka, W. (1991). “The Ethics of Inarticulacy." Inquiry 34(2): 155-182.

Lea, S., Slater, A., Ryan C. (1996). "Perception of object unity in chicks: A comparison with the human infant," Infant Behavior and Development, 19/4: 501-4.

McMahan, J. (2003). The Ethics of Killing: Problems at the Margins of Life. Oxford University Press, New York.

Meltzoff, A. and Moore, M. (1977). "Imitation of Facial and Manual Gestures by Human Neonates" Science, 198: 75-8.

Meltzoff, A. and Moore, M. (1983). “Newborn Infants Imitate Adult Facial Gestures," Child Development, 54: 702-9.

Nagel, T. (1979). Mortal Questions. Cambridge University Press, Cambridge.

Nicol, C. and Pope S. (2005). "The maternal feeding display of domestic hens is sensitive to to perceived chick error," Animal Behaviour, 52 /4: 767-74.

Regolin, L., Vallortigara, G. and Zanforlin, M. (1994). "Perceptual and motivational aspects of detour behaviour in young chicks," Animal Behaviour 47 /2: 123-31.

Regolin L., Vallortigara, G. and Zanforlin, M. (1995). “Detour behaviour in the domestic chick: Searching for a disappearing prey or a disappearing social partner," Animal Behaviour 49/2: 195-9.

Regolin, L. Rugani, R., Pagni, P., and Vallortigara, G. (2005). “Delayed search for social and nonsocial goals by young domestic chicks, Gallus gallus domesticus, Animal Behaviour, 70/4: 855-64.

Rogers L. and Kaplan G. (2004). "Preface," in Comparative Vertebrate Cognition: Are Primates Superior to Non-Primates?, Rogers L. and Kaplan G (eds.), New York: Kluwer Academic. 
Salva O., Daisley J., Regolin L., Vallortigara, G. (2009). “Lateralization of social learning in the domestic chick, Gallus gallus domesticus: learning to avoid," Animal Behaviour (electronic preprint), doi: 10.1016/j.anbehav.2009.06.021.

Sapontzis S. (1987). Sapontzis, S. F. (1987). Morals, Reason and Animals. Temple University Press, Philadelphia.

Singer P. (1990). Animal Liberation. Second Edition. New York Review of Books, New York.

Singer, P. (1993). Practical Ethics. Second Edition. Cambridge University Press, Cambridge.

Taylor, P., Haskell, M., Appleby, M. and Waran N., (2002). "Perception of time duration by domestic hens," Applied Animal Behavior Science, 76/1: 41-51.

Tooley, M. (1983). Abortion and Infanticide. Oxford University Press, Oxford.

Velleman, J. D. (2000). “Well-Being and Time." Pp 56-84 in his The Possibility of Practical Reason. Oxford University Press, Oxford.

Vallortigara, G. (2004). "Visual Cognition and Representation in Birds and Primates," in Comparative Vertebrate Cognition: Are Primates Superior to Non-Primates?, Rogers L. and Kaplan G (eds.). New York: Kluwer Academic.

Vallortigara. G., Regolin, L., Rigoni, M. and Zanforlin., M. (1998). “Delayed search for a concealed imprinted object in the domestic chick, Animal Cognition, 1/1: 17-24.

Varner, G. (forthcoming). Personhood and Animals in the Two-Level Utilitarianism of R. M. Hare. Oxford University Press, Oxford. 